\title{
Coordinating a Supply Chain with a Loss-Averse Retailer under Yield and Demand Uncertainties
}

\author{
Weiwei Luo, ${ }^{1,2}$ Dongguo Shao, ${ }^{1}$ Wei Liu, ${ }^{2}$ and Zhuomin Wang ${ }^{1}$ \\ ${ }^{1}$ State Key Laboratory of Water Resources \& Hydropower Engineering Science, Wuhan University, Wuhan 430072, China \\ ${ }^{2}$ Department of Basic Science, Military Economics Academy, Wuhan 430035, China
}

Correspondence should be addressed to Dongguo Shao; dgshao@whu.edu.cn

Received 24 April 2016; Revised 1 July 2016; Accepted 5 July 2016

Academic Editor: Paolo Renna

Copyright (C) 2016 Weiwei Luo et al. This is an open access article distributed under the Creative Commons Attribution License, which permits unrestricted use, distribution, and reproduction in any medium, provided the original work is properly cited.

\begin{abstract}
This paper investigates the channel coordination of a supply chain (SC) consisting of a loss-averse retailer and a risk-neutral supplier under yield and demand uncertainties. Three existing contracts are analyzed. Our results demonstrate that the buyback (BB) and quantity flexibility (QF) contracts can not only coordinate the supply chain but also lead to Pareto improvement for each player, while the wholesale price (WP) contract fails to coordinate the chain due to the effects of double marginalization and risk preference. For comparison, a chain with a risk-neutral retailer is also analyzed. Furthermore, numerical examples are provided to demonstrate the effectiveness of the coordination contracts, and the impacts of loss aversion and random yield on the decision-making behaviors and system performance are then discussed.
\end{abstract}

\section{Introduction}

Due to various factors, such as unpredictable machine breakdowns, complicated production processes, and labor strikes, the output quantity of production or logistics processes is often related to random yield; this is prevalent in the agricultural and high-tech industries [1]. For example, the yield of automotive plastic bumpers typically does not exceed $75 \%$ and that of chips in semiconductor manufacturing is usually less than $50 \%$ [2]. The demand side is affected by various factors (e.g., extreme weather events and economic crises) and thus can never be anticipated exactly. In general, the existence of yield and demand uncertainties results in lower system performance [3]. Therefore, the issues of random yield and demand are matters of great concern in supply chain (SC) management.

It is well known that double marginalization prevails in SC management [4] and negatively affects SC performance. To resolve this problem, various contracts have been proposed to coordinate the behavior of SC agents and improve the system-wide efficiency. The majority of SC literature focuses on a few popular types of contracts, such as wholesale price (WP), buyback (BB), revenue sharing (RS), quantity discount (QD), sales rebate (SR), and quantity flexibility
(QF). Cachon [5] and Tsay et al. [6] provided good reviews of these studies.

Traditional SC contract models are based on risk neutrality such that decision makers will select production/order quantities to maximize their expected profit. However, considerable evidence indicates that their decisions frequently deviate from maximizing expected profit [7-9]. Anupindi and Bassok [10] noted that relaxing the assumption of risk neutrality is useful in understanding SC behaviors. Recently, researchers have employed loss aversion in place of risk neutrality to describe agents' decision-making behaviors. Loss aversion is a key feature of prospect theory and indicates that people are more averse to losses when confronted with equivalent losses and gains [11]. Since loss aversion is intuitively appealing and supported in fields such as finance, marketing, and economics, SC management based on loss aversion has gradually attracted considerable attention in academia [12-19].

This study investigates channel coordination by considering both the loss-averse preference and random yield. As shown in the literature review (Section 2), the effect of loss aversion is well understood for SC with stochastic demand and reliable supply, but little is known about the role of loss aversion in channel coordination with unreliable supply 
and random demand. As stated by Bassok et al. [20], this setting is realistic in many industries, especially those with make-to-order operation. We consider a single-period, twoechelon SC consisting of a supplier and a retailer facing yield and demand uncertainty. Assume that the supplier, which is a large firm, is risk-neutral, and the retailer, which is a smaller firm, is loss-averse. To the best of our knowledge, this problem has not yet been studied in the literature. We focus on the following questions: (1) how will a loss-averse retailer determine his optimal order quantity under random yield and demand?, (2) does the coordination ability of the existing contracts change?, and (3) how will the retailer's level of loss aversion and random yield affect the decision-making behaviors and the SC performance?

The primary contributions of this study are as follows. First, SC models are developed by jointly considering random yield and loss aversion. Second, we analyze the optimal order policy and coordination ability of decentralized SC under three traditional coordination contracts (WP, BB, and QF). These three contracts are selected because they are popular and have been extensively studied in the SC literature. Our analyses show that the $\mathrm{BB}$ and $\mathrm{QF}$ contracts can coordinate the SC and achieve Pareto improvement for each member firm, while the WP contract fails to coordinate the chain. Finally, our results provide insights into the effects of loss aversion and random yield on decision-making behaviors and system performance.

The remainder of this paper is organized as follows. We review the related literature in Section 2. Then, our model and the centralized solution are proposed in Section 3. We present the contracts that coordinate the chain for the decentralized case in Section 4. The numerical experiments are given to provide some insights in Section 5. Finally, we present some concluding comments and suggestions for future research in Section 6.

\section{Literature Review}

Our work touches upon two areas of SC management research. The research that considers SC management with random yield and stochastic demand is discussed first. Shih [26] initially studied the stochastically proportional yield model and provided closed-form solutions for the optimal quantity under a centralized SC. Wang [27] compared the traditional SC model (WP contract) with a vendor-managed inventory arrangement under random yield and demand. He characterized the optimal production/inventory decisions under both arrangements. Mukhopadhyay and Ma [28] proposed a model to evaluate the optimal procurement and production decisions with random yield of returned products and random demand under three different scenarios. Güler and Bilgic [29] considered the coordination of an assembly system for an arbitrary number of suppliers with random yield and proposed two mixed types of contracts to coordinate the chain under forced compliance. Güler [30] studied the same setting, but he employed only two payment schemes and proposed four contracts. He showed that the contracts can coordinate the chain and enable arbitrary profit allocation. He and Zhang [31] studied the supplier commitment contract in the risk sharing case and further addressed the SC with a non-yield-dependent and a yield-dependent secondary market price. He and Zhao [32] investigated the inventory, production, and contracting decisions of a three-echelon SC with both demand and supply uncertainty. However, the decision makers in these studies were generally assumed to be risk-neutral.

Many alternative optimization objective models that were originally proposed in finance field, such as mean-variance analysis $[33,34]$, value-at-risk $[35,36]$, and conditional valueat-risk [35, 37], have been used by various researchers for risk analysis. In particular, research on SC management with loss-averse agents has received increasing interest over the past decade and is most related to our paper. Schweitzer and Cachon [8] initially addressed the loss-averse newsvendor problem without shortage cost. Since then, considerable effort has been devoted to extending their model to different aspects of inventory management. For example, Wang and Webster [14] considered shortage cost and investigated the impact of loss aversion on the optimal order quantity. Ma et al. [17] studied the loss-averse newsvendor model with two ordering opportunities and demand information updating. They derived the optimal ordering decisions at both ordering stages. Ma et al. [18] addressed the loss-averse inventory problem with financial constraints in a periodic review setting. Lee et al. [19] used an S-shaped utility function to investigate agile SC optimal design problems in the presence of strategic and loss-averse consumers.

Nonetheless, studies on SC coordination with a lossaverse decision maker are relatively limited. Zhang et al. [38] studied the issue of channel coordination with a loss-averse newsvendor and demonstrated that the SC can achieve channel coordination under $\mathrm{BB}$, target rebate, and incremental BB contracts. Wang and Webster [21] analyzed an SC in which a risk-neutral manufacturer sells a perishable product to a loss-averse retailer. There are distribution-free gain/losssharing and buyback contracts that can coordinate the SC and arbitrarily allocate the expected SC profit between the members. Liu et al. [22] discussed the coordination issue of the SC with a loss-averse retailer under a QF contract and demonstrated that the SC can achieve coordination by regulating the degree of flexibility and adjusting the wholesale price. Li and Wang [23] investigated the channel coordination with a loss-averse retailer facing stochastic demand that is sensitive to sales efforts. However, these studies only investigated demand uncertainty while neglecting random yield.

In addition to the studies mentioned above, the works by Liu et al. [24] and Güler and Keskin [25] are similar to our study. Liu et al. [24] investigated a loss-averse newsvendor model with random yield and demand that considered both a shortage cost setting and no shortage cost setting. They derived the optimal order quantity and analyzed the impact of loss aversion. However, the coordination mechanism between the supplier and the retailer was not considered. Güler and Keskin [25] analyzed the coordination ability of contracts (WP, BB, QF, RS, and QD) in an SC with random yield and random demand. They found that the randomness of the yield does not affect the coordination ability but changes the structure of the contract parameters. However, 
TABLE 1: Similarities and key differences between our paper and other relevant papers.

\begin{tabular}{|c|c|c|c|c|c|c|c|c|c|}
\hline Literature & [17] & {$[18]$} & {$[19]$} & {$[21]$} & {$[22]$} & {$[23]$} & {$[24]$} & {$[25]$} & $\begin{array}{c}\text { Our } \\
\text { paper }\end{array}$ \\
\hline $\begin{array}{l}\text { Loss-averse } \\
\text { player }\end{array}$ & Yes & Yes & Yes & Yes & Yes & Yes & Yes & No & Yes \\
\hline Random yield & No & No & No & No & No & No & Yes & Yes & Yes \\
\hline Random demand & Yes & Yes & Yes & Yes & Yes & Yes & Yes & Yes & Yes \\
\hline Coordination & No & No & No & Yes & Yes & Yes & No & Yes & Yes \\
\hline Multiple retailers & No & No & Yes & No & No & No & No & No & No \\
\hline $\begin{array}{l}\text { Demand } \\
\text { information } \\
\text { updating or } \\
\text { financial } \\
\text { constraint }\end{array}$ & Yes & Yes & No & No & No & No & No & No & No \\
\hline
\end{tabular}

the risk preference of decision makers is not considered in their study. In our paper, we integrate these two studies and investigate the SC coordination problem of the existing contracts where the loss-averse retailer faces both random yield and demand. The objective is to design the contracts to provide a win-win situation between the two members. Table 1 summarizes the similarities and key differences between the most relevant literature and our paper.

\section{Model and Centralized Setting}

We consider an SC consisting of a risk-neutral supplier and a loss-averse retailer. At the beginning of the selling season, the retailer orders products from the supplier to meet a random demand. The supplier employs a make-to-order policy, and the retailer is assumed to be subject to a random yield risk. We depict the risk with a stochastically proportional yield model, that is, the fraction of good units is a random variable that is independent from the production amount $[26,39]$. After the products are delivered, the retailer performs a $100 \%$ inspection; then the retailer pays for the good units and returns the defective units to the supplier. If the realized demand is smaller than the nondefective products, then the remaining products are salvaged. Otherwise, the unsatisfied demand is lost. For convenience, the notations used in this paper are defined as follows:

$Q$ : order/production quantity.

$X$ : random demand with mean $\mu_{a}$. Its probability density function (PDF) is $f(x)$, and its cumulative distribution function (CDF) is $F(x)$. Let $\bar{F}(x)=1-$ $F(x)$ denote the tail distribution.

$Y$ : random yield rate; that is, the amount of good units is $Y Q$. Its PDF and CDF are $g(y)$ and $G(y)$, respectively. $Y \in\left[y_{1}, y_{2}\right]\left(0<y_{1}<y_{2} \leq 1\right)$ is independent of $X$ and its mean is $\mu_{b}$.

$c$ : the unit production cost of the supplier.

$p$ : the retail price of the retailer per unit.

$w$ : the wholesale price of the supplier per unit.

$v$ : the unit salvage value of unsold products.
In addition, assuming that the inspection time, inspection cost, shortage cost, and salvage of defective products are negligible, the following relationship is obtained: $p>w>$ $c / \mu_{b}>v$, where $c / \mu_{b}$ is the supplier's effective per unit production cost. We use the superscripts $T, S$, and $R$ to denote the joint firm, supplier, and retailer, respectively. Subscripts 1,2 , and 3 are used to indicate $\mathrm{WP}, \mathrm{BB}$, and $\mathrm{QF}$ contracts, respectively.

To establish a performance benchmark, we first analyze the optimal solution of an integrated chain. In the centralized setting, the supplier owns a retail channel and acts as central planner for the whole SC. The objective is to maximize the total expected profit by selecting the production quantity $Q$. The expected integrated SC profit is given by

$$
\begin{aligned}
& E\left[\pi^{T}(Q)\right] \\
& =\int_{y_{1}}^{y_{2}} \int_{0}^{y \mathrm{Q}}[p x+v(y \mathrm{Q}-x)] f(x) \mathrm{d} x \mathrm{~d} G(y) \\
& \quad+\int_{y_{1}}^{y_{2}} \int_{y \mathrm{Q}}^{\infty} p y Q f(x) \mathrm{d} x \mathrm{~d} G(y)-c \mathrm{Q} .
\end{aligned}
$$

The first and second terms in (1) correspond to overstock and out-stock scenarios, respectively. The third term is the total production cost. Güler and Keskin [25] have demonstrated that $E\left[\pi^{T}(Q)\right]$ is concave in $Q$ and the optimal production/order quantity $Q^{*}$ for an integrated firm satisfies

$$
\int_{y_{1}}^{y_{2}} y F\left(y Q^{*}\right) d G(y)=\frac{p \cdot \mu_{b}-c}{p-v} .
$$

\section{Decentralized Setting}

In the decentralized setting, the risk-neutral supplier and the loss-averse retailer are independent agents. Therefore, the loss-averse retailer considers only his/her own objectives and will select an optimal order quantity to maximize his/her expected utility. Similar to Ma et al. [17] and Shen et al. [40], the retailer's loss-aversion utility function can be defined as follows:

$$
U\left(\pi^{R}\right)=\pi^{R}-(\lambda-1)\left(\beta-\pi^{R}\right)^{+}
$$

where $\lambda \geq 1$ is the loss aversion coefficient, $\beta$ is the reference target profit, and $\left(\beta-\pi^{R}\right)^{+}=\max \left(\beta-\pi^{R}, 0\right)$. If $\lambda=1$, then the retailer is risk-neutral. Higher values of $\lambda$ imply higher levels of loss aversion. Without loss of generality, we normalize $\beta=0$. Wang and Webster [21] showed that due to the presence of double marginalization and a loss-averse preference, the retailer's decision in the decentralized setting always results in system inefficiency. To encourage the retailer to order more and coordinate the SC, the supplier should provide proper contracts. Similar to Gan et al. [41] and Chen and Xiao [42], SC coordination with a loss-averse retailer is defined as follows. 
Definition 1. The SC is coordinated if the following conditions are satisfied:

(1) The order quantity of the decentralized system is equivalent to that of the centralized one.

(2) Under the contract, both the risk-neutral supplier and loss-averse retailer obtain payoffs that are not less than their respective payoffs without coordination.

It is worth mentioning that if the mechanism achieves channel coordination (the first condition) but cannot assure Pareto improvement for each player (the second condition), then the contract will be infeasible because achieving channel coordination may result in one of the members being worse off. In the following, three different contracts are investigated to coordinate the SC.

4.1. Wholesale Price Contract. The WP contract is popular because of its simplicity and lower administration cost. With a WP contract, the retailer pays an exogenous wholesale price $w_{1}$ for each product. The retailer's expected profit function under a WP contract is

$$
\pi_{1}^{R}= \begin{cases}p x+v(y Q-x)-w_{1} y Q, & x<y Q, \\ p y Q-w_{1} y Q, & x \geq y Q .\end{cases}
$$

Then, the expected utility function of the retailer, denoted by $E\left[U\left(\pi_{1}^{R}\right)\right]$, can be written as

$$
E\left[U\left(\pi_{1}^{R}\right)\right]=\int_{y_{1}}^{y_{2}} \int_{0}^{\infty} U\left(\pi_{1}^{R}\right) f(x) g(y) \mathrm{d} x \mathrm{~d} y .
$$

To calculate $E\left[U\left(\pi_{1}^{R}\right)\right]$, we divide the region of integration into three subregions, as illustrated in Figure 1. Let $Q\left(w_{1}\right)=$ $\left(w_{1}-v\right) y \mathrm{Q} /(p-v)$ denote the retailer's breakeven selling quantity function. If the realized demand $x$ is less than $Q\left(w_{1}\right)$, then the retailer faces losses in $S_{1}$. Otherwise, the retailer realizes gains in $S_{2}$ and $S_{3}$. Thus, we can rearrange the retailer's expected utility as follows:

$$
\begin{aligned}
& E\left[U\left(\pi_{1}^{R}\right)\right]=\lambda \iint_{S_{1}} \pi_{1}^{R} f(x) g(y) \mathrm{d} x \mathrm{~d} y \\
& \quad+\iint_{S_{2} \cup S_{3}} \pi_{1}^{R} f(x) g(y) \mathrm{d} x \mathrm{~d} y=(\lambda-1) \\
& \quad \cdot \int_{y_{1}}^{y_{2}} \int_{0}^{\mathrm{Q}\left(w_{1}\right)}\left[p x+v(y Q-x)-w_{1} y \mathrm{Q}\right] f(x) \\
& \cdot g(y) \mathrm{d} x \mathrm{~d} y \\
& \quad+\int_{y_{1}}^{y_{2}} \int_{0}^{y \mathrm{Q}}\left[p x+v(y Q-x)-w_{1} y \mathrm{Q}\right] f(x) \\
& \cdot g(y) \mathrm{d} x \mathrm{~d} y+\int_{y_{1}}^{y_{2}} \int_{y \mathrm{Q}}^{+\infty}\left(p y \mathrm{Q}-w_{1} y \mathrm{Q}\right) \\
& \cdot f(x) g(y) \mathrm{d} x \mathrm{~d} y .
\end{aligned}
$$

The following proposition shows the concavity of $E\left[U\left(\pi_{1}^{R}\right)\right]$ and the coordination ability of the WP contract.

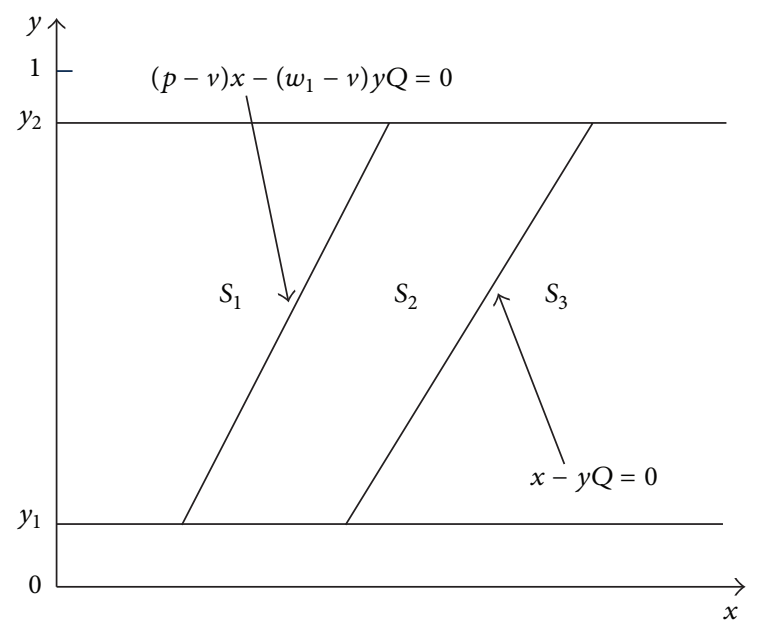

FIgURE 1: A graphical presentation of the demand and the yield rate under a WP contract.

Proposition 2. Under the WP contract, $E\left[U\left(\pi_{1}^{R}\right)\right]$ is concave in $Q$, and there is a finite and unique optimal order quantity $Q_{1}^{*}$ that satisfies

$$
\begin{aligned}
& {\left[\left(p-w_{1}\right) \cdot \mu_{b}-(p-v) \int_{y_{1}}^{y_{2}} y F\left(y Q_{1}^{*}\right) \mathrm{d} G(y)\right]} \\
& \quad-(\lambda-1)\left(w_{1}-v\right) \int_{y_{1}}^{y_{2}} y F\left[\frac{\left(w_{1}-v\right) y Q_{1}^{*}}{p-v}\right] \mathrm{d} G(y) \\
& =0 .
\end{aligned}
$$

Furthermore, the retailer's optimal order quantity $Q_{1}^{*}$ is smaller than the integrated firm's optimal order quantity $Q^{*}$. Thus, the WP contract cannot coordinate the SC.

All the proofs are shown in the Appendix. Proposition 2 shows that the loss-averse retailer will order less than the integrated SC's optimal inventory level; thus SC cannot be coordinated. This can be explained by two aspects: the double marginalization that is reflected in the first term of (7) and the loss aversion that is reflected in the second term of (7). Specifically, the retailer becomes more conservative as the level of loss aversion increases, which explains the existence of decision bias in the experiment conducted by Brown and Tang [43]. Note that, in the case with risk-averse players, although the double marginalization effect will reduce the retailer's order quantity, the risk-averse characteristic may eliminate this effect and improve the system performance under certain conditions (see, e.g., [37, 44, 45]). Thus, the risk-averse player may have different behavior than the lossaverse one.

4.2. Buyback Contract. The BB agreement is commonly used in SC and known as a return policy. The BB contract $\left(w_{2}, b\right)$ specifies that the retailer orders products at wholesale price $w_{2}$, and the supplier pays the retailer $b$ for each unsold unit at the end of the selling season. It is assumed that $v<b<w_{2}$ for 
obvious reasons. For any given realized demand $x$ and yield rate $y$, the retailer's expected profit and utility are

$$
\begin{gathered}
E\left[\pi_{2}^{R}\right]=\int_{y_{1}}^{y_{2}}\left(\int_{0}^{y \mathrm{Q}}[p x+b(y \mathrm{Q}-x)] f(x) \mathrm{d} x\right. \\
\left.+\int_{y \mathrm{Q}}^{\infty} p y \mathrm{Q} f(x) \mathrm{d} x-w_{2} y \mathrm{Q}\right) \mathrm{d} G(y), \\
E\left[U\left(\pi_{2}^{R}\right)\right]=(\lambda-1) \\
\cdot \int_{y_{1}}^{y_{2}} \int_{0}^{\mathrm{Q}\left(w_{2}, b\right)}\left[p x+b(y \mathrm{Q}-x)-w_{2} y \mathrm{Q}\right] \\
\cdot f(x) \mathrm{d} x \mathrm{~d} G(y)+E\left[\pi_{2}^{R}\right],
\end{gathered}
$$

respectively, where $Q\left(w_{2}, b\right)=\left(w_{2}-b\right) y Q /(p-b)$ denotes the retailer's breakeven quantity function under the $\mathrm{BB}$ contract. By replacing $v$ and $w_{1}$ with $b$ and $w_{2}$ in (6), respectively, we can obtain (9). Similar to the proof of Proposition 2, the following proposition for the retailer's optimal order quantity under the $\mathrm{BB}$ contract can be directly derived.

Proposition 3. Under a BB contract,

(1) there is a finite and unique optimal order quantity $Q_{2}^{*}$ that satisfies

$$
\begin{aligned}
& \left(p-w_{2}\right) \mu_{b}-(p-b) \int_{y_{1}}^{y_{2}} y F\left(y Q_{2}^{*}\right) \mathrm{d} G(y) \\
& \quad-(\lambda-1)\left(w_{2}-b\right) \int_{y_{1}}^{y_{2}} y F\left[\frac{\left(w_{2}-b\right) y Q_{2}^{*}}{p-b}\right] \mathrm{d} G(y) \\
& =0
\end{aligned}
$$

(2) $Q_{2}^{*}$ is increasing in b but decreasing in $w_{2}$ and $\lambda$.

Proposition 3 identifies the existence and uniqueness of the retailer's optimal order quantity $Q_{2}^{*}$ and the effects of $b$, $w_{2}$ and $\lambda$ on $Q_{2}^{*}$. The more loss-averse the retailer is, the smaller his optimal order quantity will be. This conclusion is consistent with the case of complete yield presented by Wang and Webster [14]. Moreover, the effects of buyback price and wholesale cost on the optimal order quantity are consistent with common sense.

Proposition 4. Under the optimal BB contract,

(1) for a given $w_{2}$, there is a unique $b^{*} \in\left[v, w_{2}\right]$ that can coordinate the SC and $b^{*}$ satisfies

$$
\begin{aligned}
& -(\lambda-1)\left(w_{2}-b^{*}\right) \int_{y_{1}}^{y_{2}} y F\left[\frac{\left(w_{2}-b^{*}\right) y Q^{*}}{p-b^{*}}\right] \mathrm{d} G(y) \\
& -\left(p-b^{*}\right) \int_{y_{1}}^{y_{2}} y F\left(y Q^{*}\right) \mathrm{d} G(y)+\left(p-w_{2}\right) \mu_{b}=0 ;
\end{aligned}
$$

(2) $b^{*}$ is increasing in $\lambda$ and $w_{2}$.
Proposition 4 shows that the buyback contract $\left(w_{2}, b\right)$ can always coordinate the SC with a loss-averse retailer. Furthermore, by selecting an appropriate $w_{2}$ or $b$, the retailer's expected utility is always higher than that under the WP contract, and the supplier's expected profit is not less than that without coordination; that is, $E\left[U\left(\pi_{2}^{R}\right)\right] \geq E\left[U\left(\pi_{1}^{R}\right)\right]$ and $E\left(\pi_{2}^{S}\right) \geq E\left(\pi_{1}^{S}\right)$. In addition, the higher the wholesale price or the level of loss aversion is, the greater the buyback credit $b^{*}$ is. For comparison, we examine a BB contract without considering loss aversion and give the following proposition.

Proposition 5. Under a BB contract without considering loss aversion,

(1) if the optimal wholesale price $w_{2}^{*}=\left[b\left(\mu_{b} \cdot p-c\right)+p(c-\right.$ $\left.\left.\mu_{b} \cdot v\right)\right] / \mu_{b}(p-v)$, then the contract can coordinate the $S C$;

(2) the optimal expected profit can be arbitrarily allocated between the supplier and the retailer;

(3) the wholesale price and the supplier's expected profit are increasing in the buyback price.

Proposition 5 shows that the buyback credit eliminates the double marginalization and further influences the allocation of the expected profit between the firms. As Cachon [5] stated, if a contract can arbitrarily allocate the SC profit, then neither firm's profit is worse off, and at least one firm is strictly better off.

4.3. Quantity Flexibility Contract. QF contracts have been widely employed by companies such as IBM, Solectron, and Toyota [46]. Under a QF contract $\left(w_{3}, \eta\right)$, the supplier charges the retailer a unit wholesale price $w_{3}$ but offers the retailer limited flexibility in adjusting the initial order quantity at the start of the selling season. Suppose that the retailer initially orders quantity $Q$ based on preliminary demand forecasts. After receiving actual demand information, he has an opportunity to revise the initial order $Q$ to be anywhere within $[\eta Q, Q]$, where $\eta \in[0,1]$ is the minimum purchase rate for the retailer. Therefore, the retailer's profit under a $\mathrm{QF}$ contract with random yield is

$$
\pi_{3}^{R}= \begin{cases}(p-v) x-\left(w_{3}-v\right) \eta y Q, & x \leq \eta y Q, \\ \left(p-w_{3}\right) x, & \eta y Q<x<y Q \\ \left(p-w_{3}\right) y Q, & x \geq y Q .\end{cases}
$$

Then, the expected utility function of the retailer can be written as

$$
E\left[U\left(\pi_{3}^{R}\right)\right]=\int_{y_{1}}^{y_{2}} \int_{0}^{\infty} U\left(\pi_{3}^{R}\right) f(x) g(y) \mathrm{d} x \mathrm{~d} y .
$$

Similarly, we can divide the region of integration into four subregions, as illustrated in Figure 2. The retailer's profit $\pi_{3}^{R}$ is 


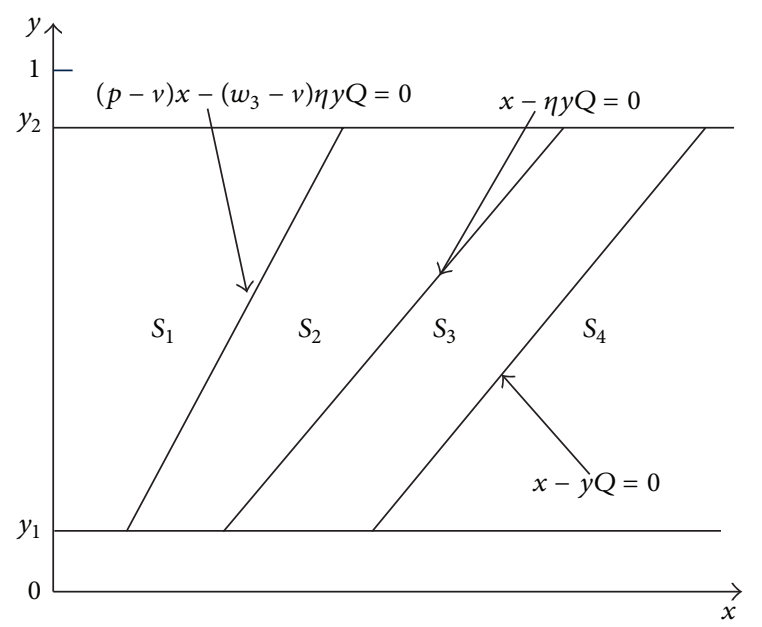

FIgURE 2: A graphical presentation of the demand and the yield rate under a QF contract.

negative in $S_{1}$ and positive in $S_{2}, S_{3}$, and $S_{4}$. Then, $E\left[U\left(\pi_{3}^{R}\right)\right]$ is rewritten as follows:

$$
\begin{aligned}
& E\left[U\left(\pi_{3}^{R}\right)\right]=\lambda \iint_{S_{1}} \pi_{3}^{R} f(x) g(y) \mathrm{d} x \mathrm{~d} y \\
& +\iint_{S_{2} \cup S_{3} \cup S_{4}} \pi_{3}^{R} f(x) g(y) \mathrm{d} x \mathrm{~d} y=-(\lambda-1) \\
& \cdot(p-v) \int_{y_{1}}^{y_{2}} \int_{0}^{\left(w_{3}-v\right) \eta y \mathrm{Q} /(p-v)} F(x) \mathrm{d} x \mathrm{~d} G(y) \\
& +\left(p-w_{3}\right) \int_{y_{1}}^{y_{2}} \int_{0}^{y \mathrm{Q}} \bar{F}(x) \mathrm{d} x \mathrm{~d} G(y)-\left(w_{3}-v\right) \\
& \quad \cdot \int_{y_{1}}^{y_{2}} \int_{0}^{\eta y Q} F(x) \mathrm{d} x \mathrm{~d} G(y) .
\end{aligned}
$$

Similar to Propositions 3-5, we analyze the existence and uniqueness of the retailer's optimal order quantity and give the following proposition.

Proposition 6. Under the QF contract,

(1) there is a unique optimal order quantity $Q_{3}^{*}$ that satisfies the following first-order optimality condition:

$$
\begin{aligned}
& \left(p-w_{3}\right) \int_{y_{1}}^{y_{2}} y \bar{F}\left(y Q_{3}^{*}\right) \mathrm{d} G(y) \\
& -\left(w_{3}-v\right) \eta \int_{y_{1}}^{y_{2}} y F\left(\eta y Q_{3}^{*}\right) \mathrm{d} G(y) \\
& -(\lambda-1)\left(w_{3}-v\right) \eta \int_{y_{1}}^{y_{2}} y F\left[\frac{\left(w_{3}-v\right) \eta y Q_{3}^{*}}{p-v}\right] \mathrm{d} G(y) \\
& =0
\end{aligned}
$$

(2) $Q_{3}^{*}$ is decreasing in $w_{3}, \lambda$, and $\eta$.
Proposition 6 indicates the effects of the wholesale cost and loss aversion coefficient on the optimal order quantity under the QF contract, which are consistent with that under the $\mathrm{BB}$ contract. Moreover, the higher the minimum purchase rate $\eta$ is, the lower the retailer's order quantity is. This is intuitive because a higher $\eta$ indicates less flexibility and increased risk of overstock for the retailer. The following results characterize the coordination ability under a $\mathrm{QF}$ contract.

Proposition 7. Under the optimal QF contract,

(1) for a given $w_{2}$, there is a unique $\eta^{*} \in[0,1]$ that can coordinate the SC, and $\eta^{*}$ satisfies

$$
\begin{gathered}
\left(p-w_{3}\right) \int_{y_{1}}^{y_{2}} y \bar{F}\left(y Q^{*}\right) \mathrm{d} G(y)-\left(w_{3}-v\right) \\
\cdot \eta^{*} \int_{y_{1}}^{y_{2}} y F\left(\eta^{*} y Q^{*}\right) \mathrm{d} G(y)-(\lambda-1)\left(w_{3}-v\right) \\
\cdot \eta^{*} \int_{y_{1}}^{y_{2}} y F\left[\frac{\left(w_{3}-v\right) \eta^{*} y Q^{*}}{p-v}\right] \mathrm{d} G(y)=0
\end{gathered}
$$

(2) $\eta^{*}$ is decreasing in $\lambda$ and $w_{3}$.

Proposition 8. Under a QF contract without considering loss aversion, the optimal expected SC profit can be arbitrarily allocated between the two agents.

Propositions 7 and 8 demonstrate that, whether considering loss aversion or not, the QF contract can always coordinate the SC with random yield and demand. Furthermore, by selecting an appropriate $w_{3}$ or $\eta$, a Pareto improvement situation can always be achieved. In addition, the higher the wholesale price or the level of loss aversion is, the lower the minimum the purchase rate $\eta^{*}$ is.

\section{Numerical Experiments}

In this section, we perform some numerical studies to demonstrate our results and obtain additional managerial insights. Assume that demand $X$ follows a truncated normal distribution with mean $\mu_{a}=500$ and standard deviation $\sigma_{a}=100$, and $Y$ follows a uniform distribution with support $[0.6,1]$. The based parameters are set as follows: $p=50$, $c=30, v=10, w_{1}=43$, and $\lambda=2$.

5.1. Efficiency of Coordination. Table 2 shows that the lossaverse retailer's optimal order quality and total expected profit under a WP contract are less than those in the centralized system. However, the BB and QF contracts can achieve SC coordination. The results indicate that the coordination is desirable. In addition, comparing these two contacts with the WP contract, the increased profits are 227.8. Let $\beta_{i}=$ $\left[E\left(\pi_{i}^{S}\right)-E\left(\pi_{1}^{S}\right)\right] / 227.8(i=2,3)$ denote the proportion of the supplier's increased profits; $\beta_{i} \in[0,1]$ is decided by the bargaining power of the two agents. Table 2 also shows that if $w_{2} \in[43.14,43.87]$ or $b^{*} \in[29.24,31.45]$, then $E\left[U\left(\pi_{2}^{R}\right)\right] \geq$ 
TABLE 2: Performance of the supply chain with different contracts.

\begin{tabular}{|c|c|c|c|c|c|c|}
\hline Models & Contract parameters & $Q^{*}$ & $E\left[U\left(\pi^{R}\right)\right]$ & $E\left(\pi^{S}\right)$ & $E\left(\pi^{T}\right)$ & $\beta$ \\
\hline Centralized model & & 540 & & & 4570.2 & \\
\hline WP contract & $\left(w_{1}=43\right)$ & 462 & 2243.5 & 2034.9 & 4342.4 & \\
\hline \multirow{2}{*}{ BB contract } & $\left(w_{2}=43.14, b^{*}=29.24\right)$ & 540 & 2512.8 & 2034.9 & 4570.2 & 0 \\
\hline & $\left(w_{2}=43.87, b^{*}=31.45\right)$ & 540 & 2245.2 & 2262.7 & 4570.2 & 1 \\
\hline \multirow{2}{*}{ QF contract } & $\left(w_{3}=43.35, \eta^{*}=0.839\right)$ & 540 & 2473.7 & 2034.9 & 4570.2 & 0 \\
\hline & $\left(w_{3}=43.97, \eta^{*}=0.822\right)$ & 540 & 2245.7 & 2262.7 & 4570.2 & 1 \\
\hline
\end{tabular}

TABLE 3: Impact of yield uncertainty on the supply chain $\left(\lambda=2, \beta_{1}=\beta_{2}=0.5\right)$.

\begin{tabular}{|c|c|c|c|c|c|c|}
\hline Models & Contract parameters & $U\left(y_{1}, y_{2}\right)$ & $Q^{*}$ & $E\left[U\left(\pi^{R}\right)\right]$ & $E\left(\pi^{S}\right)$ & $E\left(\pi^{T}\right)$ \\
\hline \multirow{3}{*}{ Centralized model } & & $(0.6,1)$ & 540 & & & 4570.2 \\
\hline & & $(0.8,1)$ & 529 & & & 6700.5 \\
\hline & & 1 & 500 & & & 8404.2 \\
\hline \multirow{3}{*}{ WP contract } & & $(0.6,1)$ & 462 & 2243.5 & 2034.9 & 4342.4 \\
\hline & $\left(w_{1}=43\right)$ & $(0.8,1)$ & 431 & 2361.7 & 3750.3 & 6176.0 \\
\hline & & 1 & 393 & 2458.3 & 5109.9 & 7569.8 \\
\hline \multirow{3}{*}{ BB contract } & $\left(w_{2}=43.16, b^{*}=36.4\right)$ & $(0.6,1)$ & 540 & 2396.7 & 2148.8 & 4570.2 \\
\hline & $\left(w_{2}=43.37, b^{*}=34.4\right)$ & $(0.8,1)$ & 529 & 2666.2 & 4012.55 & 6700.5 \\
\hline & $\left(w_{2}=43.45, b^{*}=30.2\right)$ & 1 & 500 & 2874.7 & 5527.1 & 8404.2 \\
\hline \multirow{3}{*}{ QF contract } & $\left(w_{3}=43.38, \eta^{*}=0.747\right)$ & $(0.6,1)$ & 540 & 2365.2 & 2148.8 & 4570.2 \\
\hline & $\left(w_{3}=43.65, \eta^{*}=0.781\right)$ & $(0.8,1)$ & 529 & 2629.8 & 4012.5 & 6700.5 \\
\hline & $\left(w_{3}=43.35, \eta^{*}=0.839\right)$ & 1 & 500 & 2836.8 & 5527.1 & 8404.2 \\
\hline
\end{tabular}

$E\left[U\left(\pi_{1}^{R}\right)\right]$ and $E\left(\pi_{2}^{S}\right) \geq E\left(\pi_{1}^{S}\right)$. Similarly, if $w_{3} \in[43.35,43.97]$ or $\eta^{*} \in[0.822,0.839]$, then $E\left[U\left(\pi_{3}^{R}\right)\right] \geq E\left[U\left(\pi_{1}^{R}\right)\right]$ and $E\left(\pi_{3}^{S}\right) \geq E\left(\pi_{1}^{S}\right)$. In other words, the BB and QF contracts can assure Pareto improvement for both players.

5.2. Effects of Loss Aversion. To analyze the impact of loss aversion on the retailer's optimal order quantity, we fix $w_{2}=$ $w_{3}=43$ and vary $\lambda$ from 1 to 5 in steps of 0.1 with different contract parameters $b$ and $\eta$. The optimal policies are plotted in Figures 3 and 4, respectively. These two figures show that the optimal order quantity is decreasing in $\lambda$. Thus as the loss aversion level increases, it is more difficult for the supplier to coordinate the SC. Moreover, for any given $\lambda$, the higher $b$ (lower $\eta$ ) is, the greater optimal order quantity is. These results are consistent with those presented in Propositions 3 and 6 and offer guidance for managers. As the retailer's level of loss aversion increases, the supplier should provide a higher buyback price and a lower minimum purchase rate to encourage the retailer to order more.

Then, the impacts of the loss aversion coefficient and coordinating parameters on the supplier's expected profit are analyzed. We vary $\lambda$ from 1 to 5 in steps of 0.2 , and the other parameters are the same as in Section 5.1. As shown in Figures 5 and 6, the supplier's expected profit is decreasing in $\lambda$ and $\eta^{*}$ and increasing in $b^{*}$. Intuitively, one may think that the supplier should prefer a smaller $b^{*}$ and a larger $\eta^{*}$. However, the opposite is true when the wholesale price is simultaneously adjusted to coordinate the SC. In fact, the

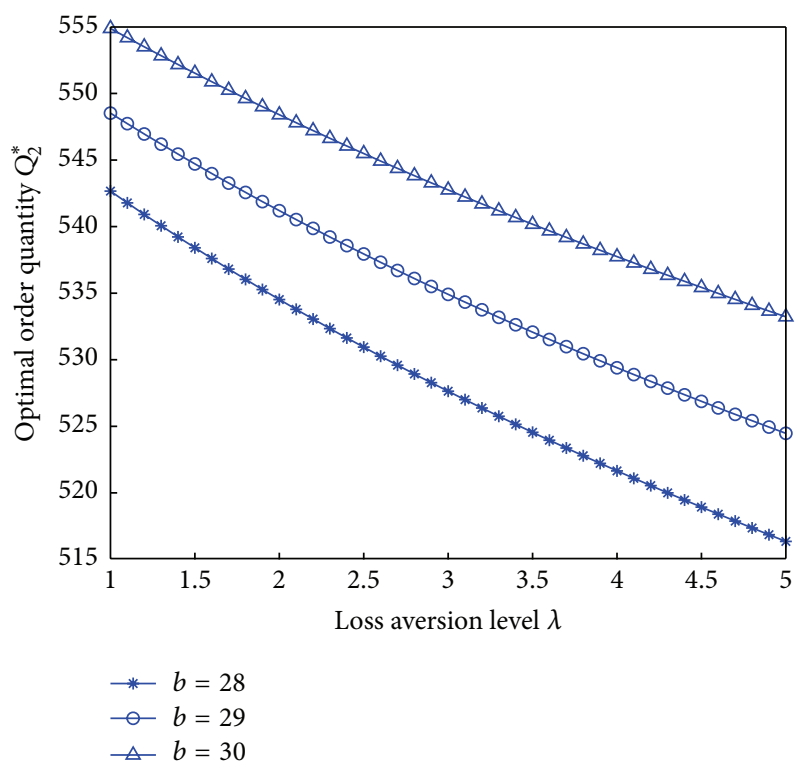

FIGURE 3: Plot of the optimal order quantity $Q_{2}^{*}$ with $\lambda$ under different values of $b$.

supplier gains more profit of the entire SC by providing a larger $b^{*}$ or smaller $\eta^{*}$.

5.3. Effects of Yield Uncertainty. Table 3 compares three different yield rates and illustrates the impact of random 


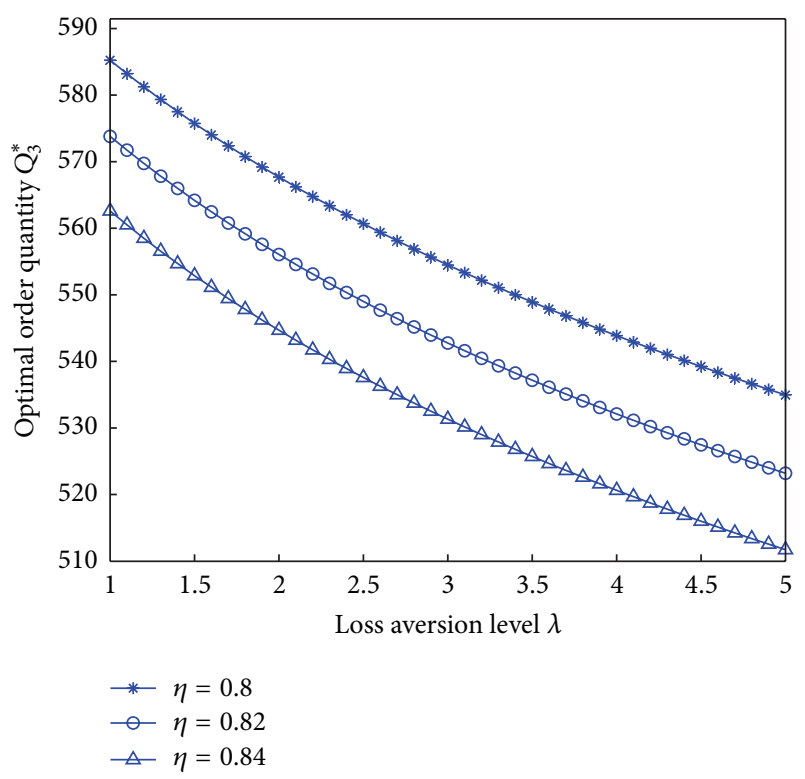

FIgURE 4: Plot of the optimal order quantity $Q_{3}^{*}$ with $\lambda$ under different values of $\eta$.

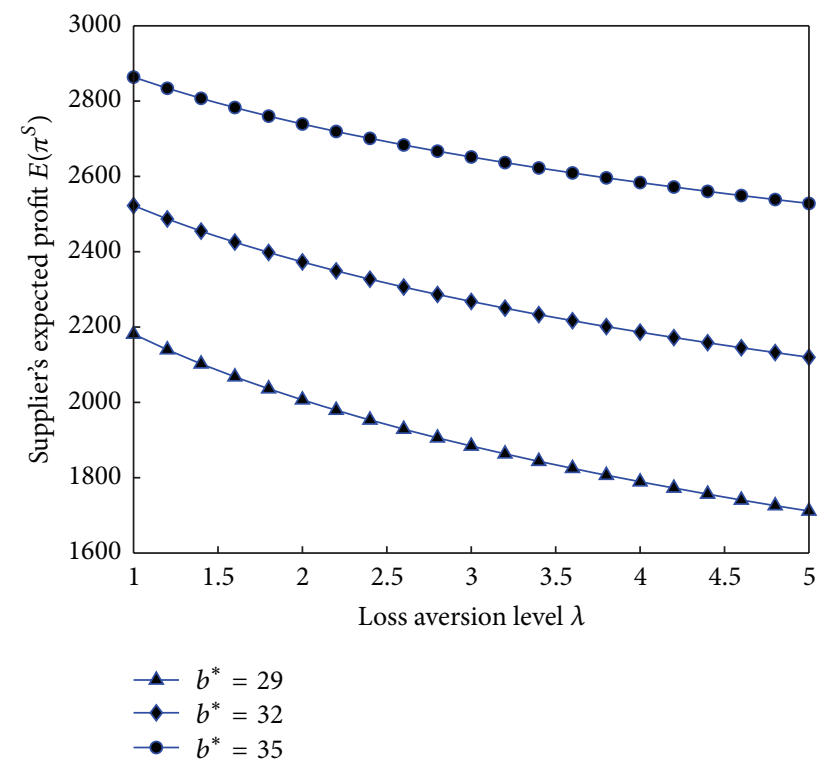

Figure 5: Plot of the supplier's expected profit with $\lambda$ under different values of $b^{*}$.

yield on SC performance. It is shown that a lower yield uncertainty generally results in higher SC performance. Specifically, as the yield randomness decreases, the supplier's effective per unit production cost $c / \mu_{b}$ also decreases; thus, his expected profit increases significantly. Moreover, although the optimal order/production quantity decreases, the retailer can benefit from the decrease in supply uncertainty. The results motivate firms to improve the random yield rate through various efforts such as new production technologies and radio frequency identification.

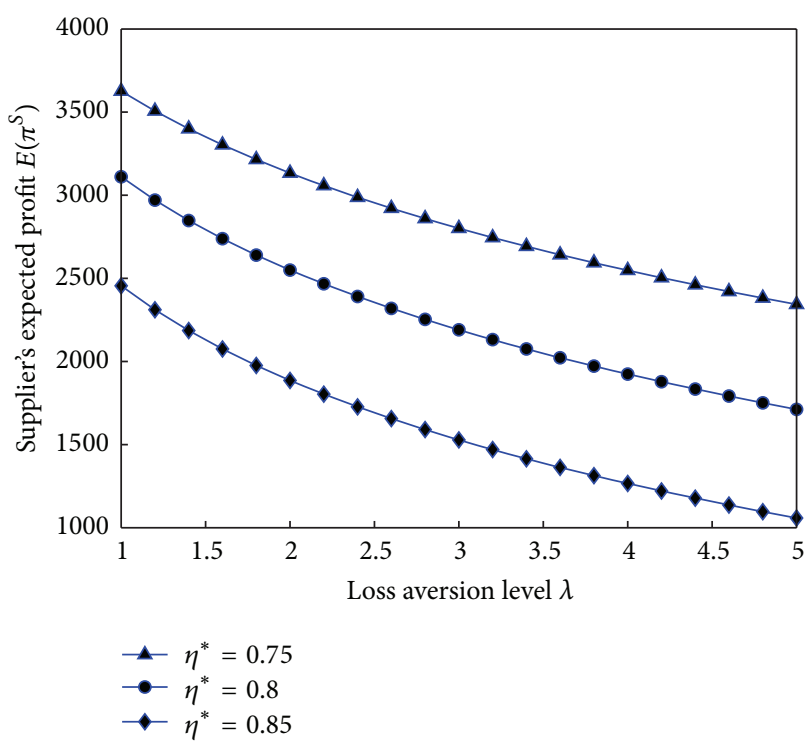

FIGURE 6: Plot of the supplier's expected profit with $\lambda$ under different values of $\eta^{*}$.

\section{Conclusion}

This paper investigates the channel coordination of an SC consisting of a loss-averse retailer and a risk-neutral supplier. We develop SC models by jointly considering random yield and loss aversion. A definition of SC coordination with a loss-averse retailer is proposed at first. Then, three wellknown types of contracts (WP, BB, and QF) are analyzed. For comparison, we also analyze the $\mathrm{BB}$ and $\mathrm{QF}$ contracts without considering loss aversion. Our analytic results demonstrate that, for each contract, the optimal order quantity is decreasing in loss aversion level. In addition, whether considering loss aversion or not, the $\mathrm{BB}$ and $\mathrm{QF}$ contracts can coordinate the SC and achieve a win-win outcome, while the WP contract remains ineffective for managing the SC when the retailer has a loss-averse preference.

Subsequently, the numerical experiments show the effectiveness of the $\mathrm{BB}$ and $\mathrm{QF}$ contracts in SC coordination. Then, the impacts of loss aversion level and random yield on the SC's decision making and performance are discussed. Our results indicate that as the loss aversion level increases, the supplier will provide a higher buyback price but a lower minimum purchase rate to encourage the retailer to place a larger order. In fact, the supplier also gains more to do so. Then, we further confirm that decreasing yield risk can improve the SC performance. These results are very helpful for the supplier when deciding how to coordinate the SC with random yield and a loss-averse retailer.

As an extension of this work, we can consider the model with a more general situation, for example, multiperiod, multiple suppliers, multiple loss-averse retailers, or asymmetric information models. Another noteworthy extension could be adopting other nonlinear utility functions to investigate the model with random yield and uncertain demand. 


\section{Appendix}

Proof of Proposition 2. The first and second derivatives of $E\left[U\left(\pi_{1}^{R}\right)\right]$ with respect to $Q$ are

$$
\begin{aligned}
& \frac{\mathrm{d} E\left[U\left(\pi_{1}^{R}\right)\right]}{\mathrm{d} Q}=-(\lambda-1)\left(w_{1}-v\right) \\
& \cdot \int_{y_{1}}^{y_{2}} y F\left[\frac{\left(w_{1}-v\right) y Q}{p-v}\right] \mathrm{d} G(y)-(p-v) \\
& \cdot \int_{y_{1}}^{y_{2}} y F(y Q) \mathrm{d} G(y)+\left(p-w_{1}\right) \mu_{b}, \\
& \frac{\mathrm{d}^{2} E\left[U\left(\pi_{1}^{R}\right)\right]}{\mathrm{d} Q^{2}}=-(\lambda-1) \frac{\left(w_{1}-v\right)^{2}}{p-v} \\
& \cdot \int_{y_{1}}^{y_{2}} y^{2} f\left[\frac{\left(w_{1}-v\right) y Q}{p-v}\right] \mathrm{d} G(y)-(p-v) \\
& \cdot \int_{y_{1}}^{y_{2}} y^{2} f(y Q) \mathrm{d} G(y)<0 .
\end{aligned}
$$

From (A.2), we know that $E\left[U\left(\pi_{1}^{R}\right)\right]$ is concave in $Q$. Furthermore, $\mathrm{d} E\left[U\left(\pi_{1}^{R}\right)\right] / \mathrm{d} Q>0$ as $Q \rightarrow 0$ and $\mathrm{d} E\left[U\left(\pi_{1}^{R}\right)\right] / \mathrm{d} Q<0$ as $Q \rightarrow \infty$. Thus the retailer's optimal order quantity $Q_{1}^{*}$ is unique and satisfies $d E\left[U\left(\pi_{1}^{R}\right)\right] / d Q=0$, that is, (7).

If the retailer is risk-neutral $(\lambda=1)$, then it follows from (7) that the retailer's optimal order quantity $\left.Q_{1}^{*}\right|_{\lambda=1}$ satisfies

$$
\int_{y_{1}}^{y_{2}} y F\left(\left.y Q_{1}^{*}\right|_{\lambda=1}\right) \mathrm{d} G(y)=\frac{\left(p-w_{1}\right) \mu_{b}}{p-v} .
$$

Comparing (A.3) and (2), then we have $\left.Q_{1}^{*}\right|_{\lambda=1}<Q^{*}$. On the other hand, from (7) it follows that the higher the retailer's loss-averse level, the lower his optimal order quantity. Thus $\left.Q_{1}^{*}\right|_{\lambda>1}<\left.Q_{1}^{*}\right|_{\lambda=1}<Q^{*}$. According to the first condition of Definition 1 , the WP contract fails to coordinate the SC.

\section{Proof of Proposition 3.}

Part (1). Proof of Proposition 3 is similar to the proof of Proposition 2.

Part (2). To simplify our analysis, let

$$
\begin{aligned}
H\left(Q_{2}^{*}\right)= & -(\lambda-1)\left(w_{2}-b\right) \\
& \cdot \int_{y_{1}}^{y_{2}} y F\left[\frac{\left(w_{2}-b\right) y Q_{2}^{*}}{p-b}\right] \mathrm{d} G(y) \\
& -(p-b) \int_{y_{1}}^{y_{2}} y F\left(y Q_{2}^{*}\right) \mathrm{d} G(y) \\
& +\left(p-w_{2}\right) \mu_{b} .
\end{aligned}
$$

Taking the first derivative of $H\left(Q_{2}^{*}\right)$ with respect to $Q_{2}^{*}, \lambda$, $w_{2}$, and $b$, respectively, then

$$
\begin{aligned}
& \frac{\partial H\left(Q_{2}^{*}\right)}{\partial Q_{2}^{*}}=-(\lambda-1) \frac{\left(w_{2}-b\right)^{2}}{p-b} \\
& \cdot \int_{y_{1}}^{y_{2}} y^{2} f\left[\frac{\left(w_{2}-b\right) y Q_{2}^{*}}{p-b}\right] \mathrm{d} G(y)-(p \\
& \text {-b) } \int_{y_{1}}^{y_{2}} y^{2} f\left(y Q_{2}^{*}\right) \mathrm{d} G(y)<0, \\
& \frac{\partial H\left(Q_{2}^{*}\right)}{\partial \lambda}=-\left(w_{2}-b\right) \\
& \int_{y_{1}}^{y_{2}} y F\left[\frac{\left(w_{2}-b\right) y Q_{2}^{*}}{p-b}\right] \mathrm{d} G(y)<0, \\
& \frac{\partial H\left(Q_{2}^{*}\right)}{\partial w_{2}}=-(\lambda-1) \\
& \left\{\int_{y_{1}}^{y_{2}} y F\left[\frac{\left(w_{2}-b\right) y Q_{2}^{*}}{p-b}\right] \mathrm{d} G(y)\right. \\
& +\frac{\left(w_{2}-b\right) Q_{2}^{*}}{p-b} \\
& \left.\cdot \int_{y_{1}}^{y_{2}} y^{2} f\left[\frac{\left(w_{2}-b\right) y Q_{2}^{*}}{p-b}\right] \mathrm{d} G(y)\right\}-\mu_{b}<0, \\
& \frac{\partial H\left(Q_{2}^{*}\right)}{\partial b}=(\lambda-1) \\
& \left\{\int_{y_{1}}^{y_{2}} y F\left[\frac{\left(w_{2}-b\right) y Q_{2}^{*}}{p-b}\right] \mathrm{d} G(y)\right. \\
& +\frac{\left(w_{2}-b\right)\left(p-w_{2}\right) Q_{2}^{*}}{(p-b)^{2}} \\
& \left.\cdot \int_{y_{1}}^{y_{2}} y^{2} f\left[\frac{\left(w_{2}-b\right) y Q_{2}^{*}}{p-b}\right] \mathrm{d} G(y)\right\} \\
& +\int_{y_{1}}^{y_{2}} y F\left(y Q_{2}^{*}\right) \mathrm{d} G(y)>0 .
\end{aligned}
$$

By using implicit function theorem, we have

$$
\begin{aligned}
& \frac{\partial Q_{2}^{*}}{\partial b}=-\frac{\partial H\left(Q_{2}^{*}\right) / \partial b}{\partial H\left(Q_{2}^{*}\right) / \partial Q_{2}^{*}}>0, \\
& \frac{\partial Q_{2}^{*}}{\partial w_{2}}=-\frac{\partial H\left(Q_{2}^{*}\right) / \partial w_{2}}{\partial H\left(Q_{2}^{*}\right) / \partial Q_{2}^{*}}<0, \\
& \frac{\partial Q_{2}^{*}}{\partial \lambda}=-\frac{\partial H\left(Q_{2}^{*}\right) / \partial \lambda}{\partial H\left(Q_{2}^{*}\right) / \partial Q_{2}^{*}}<0 .
\end{aligned}
$$
$\lambda$.

Therefore, $Q_{2}^{*}$ is increasing in $b$ but decreasing in $w_{2}$ and 
Proof of Proposition 4.

Part (1). Let

$$
\begin{aligned}
H(b)= & -(\lambda-1)\left(w_{2}-b\right) \\
& \cdot \int_{y_{1}}^{y_{2}} y F\left[\frac{\left(w_{2}-b\right) y Q^{*}}{p-b}\right] \mathrm{d} G(y)-(p-b) \\
& \cdot \int_{y_{1}}^{y_{2}} y F\left(y Q^{*}\right) \mathrm{d} G(y)+\left(p-w_{2}\right) \mu_{b},
\end{aligned}
$$

where $Q^{*}$ satisfies (2). Taking the first derivative of $H(b)$ with respect to $b$, then we can obtain $\partial H(b) / \partial b>0$, which implies that $H(b)$ is strictly increasing in $b \in\left[v, w_{2}\right]$. Since

$$
\begin{aligned}
& H\left(w_{2}\right)=\left(p-w_{2}\right) \int_{y_{1}}^{y_{2}} y F\left(y Q^{*}\right) \mathrm{d} G(y)+\left(p-w_{2}\right) \\
& \cdot \mu_{b}>0, \\
& H(v)=-(\lambda-1)\left(w_{2}-v\right) \\
& \quad \cdot \int_{y_{1}}^{y_{2}} y F\left[\frac{\left(w_{2}-v\right) y Q^{*}}{p-v}\right] \mathrm{d} G(y)-\left(w_{2}-c\right) \mu_{b} \\
& <0,
\end{aligned}
$$

then, there is a unique $b^{*} \in\left[v, w_{2}\right]$ that satisfies (11).

Part (2). By using implicit function theorem, from (11) it follows that $\partial b^{*} / \partial \lambda>0$ and $\partial b^{*} / \partial w_{2}>0$. Thus $b^{*}$ is increasing in $\lambda$ and $w_{2}$.

\section{Proof of Proposition 5.}

Part (1). If the retailer is risk-neutral, where $\lambda=1$, then from (9) the retailer's optimal order quantity satisfies

$$
\int_{y_{1}}^{y_{2}} y F\left(y Q_{2}^{*}\right) \mathrm{d} G(y)=\frac{(p-w) \mu_{b}}{p-b} .
$$

Note that Definition 1 identifies that the SC can achieve coordination when $Q_{2}^{*}=Q^{*}$. Comparing (A.9) with (2), then we have

$$
w_{2}^{*}=\frac{b\left(\mu_{b} \cdot p-c\right)+p\left(c-\mu_{b} \cdot v\right)}{\mu_{b}(p-v)} .
$$

Therefore, if the supplier chooses a wholesale price in (A.10), then the BB contract can coordinate the SC.

Part (2). Let $b^{*}=(p-v) \alpha+v$, where $0 \leq \alpha \leq 1$. Substituting it into (A.10), then $w_{2}^{*}=\left[\mu_{b} \cdot p \cdot \alpha+c(1-\alpha)\right] / \mu_{b}$. Under the BB contract, the optimal profits of the supplier and the retailer can be written as

$$
\begin{aligned}
E\left(\pi_{2}^{R}\right)= & \left(p-w_{2}^{*}\right) \int_{y_{1}}^{y_{2}} y Q_{2}^{*} \mathrm{~d} G(y) \\
& -\left(p-b^{*}\right) \int_{y_{1}}^{y_{2}} \int_{0}^{y Q_{2}^{*}} F(x) \mathrm{d} x \mathrm{~d} G(y), \\
E\left(\pi_{2}^{S}\right)= & \int_{y_{1}}^{y_{2}}\left(w_{2}^{*} y Q_{2}^{*}-c Q_{2}^{*}\right) \mathrm{d} G(y) \\
& -\left(b^{*}-v\right) \int_{y_{1}}^{y_{2}} \int_{0}^{y Q_{2}^{*}} F(x) \mathrm{d} x \mathrm{~d} G(y) .
\end{aligned}
$$

Substituting $b^{*}, w_{2}^{*}$, and $Q_{2}^{*}=Q^{*}$ into (A.11), then $E\left(\pi_{2}^{R}\right)=(1-\alpha) E\left(\pi^{T}\right)$ and $E\left(\pi_{2}^{S}\right)=\alpha E\left(\pi^{T}\right)$, where $E\left(\pi^{T}\right)$ denotes the optimal profit of the total SC. Thus, profit can be arbitrarily allocated between the supplier and the retailer by changing the value of $\alpha$.

Part (3). Substituting $w_{2}^{*}$ into (A.11), then we have

$$
\begin{aligned}
& E\left(\pi_{2}^{R}\right)=\frac{p-b}{p-v} E\left(\pi^{T}\right), \\
& E\left(\pi_{2}^{S}\right)=\frac{b-v}{p-v} E\left(\pi^{T}\right) .
\end{aligned}
$$

From (A.10) and (A.12), it follows that the wholesale price and the supplier's expected profit are increasing in the buyback price.

Proof of Proposition 6. Proof of Proposition 6 is similar to the proof of Proposition 3.

\section{Proof of Proposition 7.}

Part (1). Let

$$
\begin{aligned}
Z(\eta)=\left(p-w_{3}\right) \int_{y_{1}}^{y_{2}} y \bar{F}\left(y Q^{*}\right) \mathrm{d} G(y)-\left(w_{3}-v\right) \\
\quad \cdot \int_{y_{1}}^{y_{2}} y F\left(y Q^{*}\right) \mathrm{d} G(y)-(\lambda-1)\left(w_{3}-v\right) \\
\cdot \int_{y_{1}}^{y_{2}} y F\left(\frac{w_{3}-v}{p-v} y Q^{*}\right) \mathrm{d} G(y)
\end{aligned}
$$

After taking the first derivative of $Z(\eta)$ with respect to $\eta$, then we have $\mathrm{d} Z(\eta) / \mathrm{d} \eta<0$. Thus, $Z(\eta)$ is strictly decreasing in $\eta$. Since $Z(0)>0$ and $Z(1)<0$, then there is a unique $\eta^{*} \in[0,1]$ that satisfies $Z\left(\eta^{*}\right)=0$, that is, (16).

Part (2). By using implicit function theorem, it follows from (16) that $\partial \eta^{*} / \partial \lambda<0$ and $\partial \eta^{*} / \partial w_{3}<0$. Thus $\eta^{*}$ is decreasing in $\lambda$ and $w_{3}$. 
Proof of Proposition 8. Under the QF contract, the retailer's expected profit function is

$$
\begin{aligned}
E\left(\pi_{3}^{R}\right)= & \left(p-w_{3}\right) \int_{y_{1}}^{y_{2}} \int_{0}^{y \mathrm{Q}} \bar{F}(x) \mathrm{d} x \mathrm{~d} G(y) \\
& -\left(w_{3}-v\right) \int_{y_{1}}^{y_{2}} \int_{0}^{\eta y \mathrm{Q}} F(x) \mathrm{d} x \mathrm{~d} G(y) .
\end{aligned}
$$

Note that Proposition 7 shows that $\eta$ is strictly decreasing in $w_{3}$. When $w_{3} \rightarrow p$, then $\eta \rightarrow 0$, and thus $E\left(\pi_{3}^{R}\right) \rightarrow 0$, which indicates that the retailer's profit is almost zero. When $w_{3} \rightarrow c / \mu_{b}$, then $\eta \rightarrow 1$, and thus $E\left(\pi_{3}^{R}\right) \rightarrow E\left[\pi^{T}(Q)\right]$, which indicates that the retailer obtains nearly the entire SC profit. Since the retailer's profit is continuous in $w_{3}$ or $\eta$, the SC profit can be arbitrarily allocated between the two firms by changing $w_{3}$ or $\eta$.

\section{Competing Interests}

The authors declare that they have no competing interests.

\section{Acknowledgments}

The paper is supported by the National Natural Science Foundation of China (nos. 51379150 and 51439006).

\section{References}

[1] H. Gurnani, R. Akella, and J. Lehoczky, "Supply management in assembly systems with random yield and random demand," IIE Transactions, vol. 32, no. 8, pp. 701-714, 2000.

[2] S. E. Grasman, T. L. Olsen, and J. R. Birge, "Setting basestock levels in multi-product systems with setups and random yield," IIE Transactions, vol. 40, no. 12, pp. 1158-1170, 2008.

[3] M. Xu and Y. Lu, "The effect of supply uncertainty in pricesetting newsvendor models," European Journal of Operational Research, vol. 227, no. 3, pp. 423-433, 2013.

[4] J. J. Spengler, "Vertical integration and antitrust policy," Journal of Political Economy, vol. 58, no. 4, pp. 347-352, 1950.

[5] G. P. Cachon, "Supply chain coordination with contracts," in Handbooks in Operations Research and Management Science, vol. 11, no. 11, pp. 227-339, 2003.

[6] A. A. Tsay, S. Nahmias, and N. Agrawal, "Modeling supply chain contracts: a review," in Quantitative Models for Supply Chain Management, pp. 299-336, Springer, 1999.

[7] M. Fisher and A. Raman, "Reducing the cost of demand uncertainty through accurate response to early sales," Operations Research, vol. 44, no. 1, pp. 87-99, 1996.

[8] M. E. Schweitzer and G. P. Cachon, "Decision bias in the newsvendor problem with a known demand distribution: experimental evidence," Management Science, vol. 46, no. 3, pp. 404-420, 2000.

[9] I. Erev, E. Ert, and E. Yechiam, "Loss aversion, diminishing sensitivity, and the effect of experience on repeated decisions," Journal of Behavioral Decision Making, vol. 21, no. 5, pp. 575-597, 2008.

[10] R. Anupindi and Y. Bassok, "Supply contracts with quantity commitments and stochastic demand," in Quantitative Models for Supply Chain Management, vol. 17 of International Series in Operations Research \& Management Science, pp. 197-232, Springer, Boston, Mass, USA, 1999.

[11] D. Kahneman and A. Tversky, "Prospect theory: an analysis of decision under risk," Econometrica, vol. 47, no. 2, pp. 263-292, 1979.

[12] J. Sun and X. Xu, "Coping with loss aversion in the newsvendor model," Discrete Dynamics in Nature and Society, vol. 2015, Article ID 851586, 11 pages, 2015.

[13] J. Luo and X. Chen, "Coordination of a random yield supply chain with a loss-averse supplier," Mathematical Problems in Engineering, vol. 2015, Article ID 192147, 11 pages, 2015.

[14] C. X. Wang and S. Webster, "The loss-averse newsvendor problem," Omega, vol. 37, no. 1, pp. 93-105, 2009.

[15] C. X. Wang, “The loss-averse newsvendor game," International Journal of Production Economics, vol. 124, no. 2, pp. 448-452, 2010.

[16] W. Liu, S. J. Song, and C. Wu, "Impact of loss aversion on the newsvendor game with product substitution," International Journal of Production Economics, vol. 141, no. 1, pp. 352-359, 2013.

[17] L. J. Ma, Y. Zhao, W. Xue, T. C. E. Cheng, and H. Yan, "Lossaverse newsvendor model with two ordering opportunities and market information updating," International Journal of Production Economics, vol. 140, no. 2, pp. 912-921, 2012.

[18] L. J. Ma, W. L. Xue, Y. X. Zhao, and X. D. Lin, "Loss-averse inventory and borrowing decisions with constraints on working capital in fashion and textiles industry," Mathematical Problems in Engineering, vol. 2013, Article ID 657641, 9 pages, 2013.

[19] C. H. Lee, T.-M. Choi, and T. C. E. Cheng, "Selling to strategic and loss-averse consumers: stocking, procurement, and product design policies," Naval Research Logistics, vol. 62, no. 6, pp. 435-453, 2015.

[20] Y. Bassok, W. J. Hopp, and M. Rohatgi, "A simple linear heuristic for the service constrained random yield problem," IIE Transactions, vol. 34, no. 5, pp. 479-487, 2002.

[21] C. X. Wang and S. Webster, "Channel coordination for a supply chain with a risk-neutral manufacturer and a loss-averse retailer," Decision Sciences, vol. 38, no. 3, pp. 361-389, 2007.

[22] Y. M. Liu, S. W. Cheng, and H. Xie, "Research on supply chain quantity flexibility contract with a loss-averse preference retailer," Control and Decision, vol. 27, no. 7, pp. 975-982, 2012.

[23] L. Li and Y. Wang, "Coordinating a supply chain with a lossaverse retailer and effort dependent demand," The Scientific World Journal, vol. 2014, Article ID 231041, 12 pages, 2014.

[24] W. Liu, S. J. Song, and C. Wu, "The loss-averse newsvendor problem with random yield," Transactions of the Institute of Measurement and Control, vol. 36, no. 3, pp. 312-320, 2014.

[25] M. G. Güler and M. E. Keskin, "On coordination under random yield and random demand," Expert Systems with Applications, vol. 40, no. 9, pp. 3688-3695, 2013.

[26] W. Shih, "Optimal inventory policies when stockouts result from defective products," International Journal of Production Research, vol. 18, no. 6, pp. 677-686, 1980.

[27] C. X. Wang, "Random yield and uncertain demand in decentralised supply chains under the traditional and VMI arrangements," International Journal of Production Research, vol. 47, no. 7, pp. 1955-1968, 2009.

[28] S. K. Mukhopadhyay and H. Ma, "Joint procurement and production decisions in remanufacturing under quality and demand uncertainty," International Journal of Production Economics, vol. 120, no. 1, pp. 5-17, 2009. 
[29] M. G. Güler and T. Bilgic, "On coordinating an assembly system under random yield and random demand," European Journal of Operational Research, vol. 196, no. 1, pp. 342-350, 2009.

[30] M. G. Güler, "Coordinating decentralised assembly systems with random yield and random demand," International Journal of Production Research, vol. 53, no. 3, pp. 886-896, 2015.

[31] Y. J. He and J. Zhang, "Random yield supply chain with a yield dependent secondary market," European Journal of Operational Research, vol. 206, no. 1, pp. 221-230, 2010.

[32] Y. He and X. Zhao, "Coordination in multi-echelon supply chain under supply and demand uncertainty," International Journal of Production Economics, vol. 139, no. 1, pp. 106-115, 2012.

[33] C. H. Chiu, T. M. Choi, G. Hao, and X. Li, "Innovative menu of contracts for coordinating a supply chain with multiple meanvariance retailers," European Journal of Operational Research, vol. 246, no. 3, pp. 815-826, 2015.

[34] P. Ray and M. Jenamani, "Mean-variance analysis of sourcing decision under disruption risk," European Journal of Operational Research, vol. 250, no. 2, pp. 679-689, 2016.

[35] M. Wu, S. X. Zhu, and R. H. Teunter, "The risk-averse newsvendor problem with random capacity," European Journal of Operational Research, vol. 231, no. 2, pp. 328-336, 2013.

[36] A. Özler, B. Tan, and F. Karaesmen, "Multi-product newsvendor problem with value-at-risk considerations," International Journal of Production Economics, vol. 117, no. 2, pp. 244-255, 2009.

[37] L. J. Ma, F. M. Liu, S. J. Li, and H. M. Yan, "Channel bargaining with risk-averse retailer," International Journal of Production Economics, vol. 139, no. 1, pp. 155-167, 2012.

[38] L. Zhang, S. J. Song, and C. Wu, "Supply chain coordination of loss-averse newsvendor with contract," Tsinghua Science and Technology, vol. 10, no. 2, pp. 133-140, 2005.

[39] C. A. Yano and H. L. Lee, "Lot sizing with random yields: a review," Operations Research, vol. 43, no. 2, pp. 311-334, 1995.

[40] H. Shen, Z. Pang, and T. C. E. Cheng, "The component procurement problem for the loss-averse manufacturer with spot purchase," International Journal of Production Economics, vol. 132, no. 1, pp. 146-153, 2011.

[41] X. Gan, S. P. Sethi, and H. Yan, "Coordination of supply chains with risk-averse agents," Production and Operations Management, vol. 13, no. 2, pp. 135-149, 2004.

[42] K. B. Chen and T. J. Xiao, "Reordering policy and coordination of a supply chain with a loss-averse retailer," Journal of Industrial and Management Optimization, vol. 9, no. 4, pp. 827-853, 2013.

[43] A. O. Brown and C. S. Tang, "The impact of alternative performance measures on single-period inventory policy," Journal of Industrial and Management Optimization, vol. 2, no. 3, pp. 297318, 2006.

[44] T. M. Choi, D. Li, H. Yan, and C.-H. Chiu, "Channel coordination in supply chains with agents having mean-variance objectives," Omega, vol. 36, no. 4, pp. 565-576, 2008.

[45] L. J. Ma, J. B. Li, and H. F. Wang, "Coordinate the supply chain with risk-averse agents under CVaR criteria," in Proceedings of the International Conference on Management and Service Science (MASS '10), pp. 1-4, August 2010.

[46] A. A. Tsay, "The quantity flexibility contract and suppliercustomer incentives," Management Science, vol. 45, no. 10, pp. 1339-1358, 1999. 


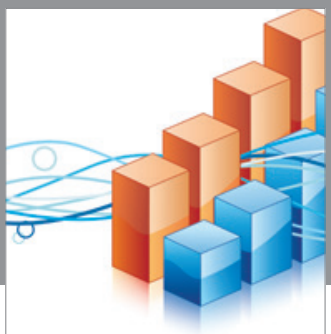

Advances in

Operations Research

vatem alat4

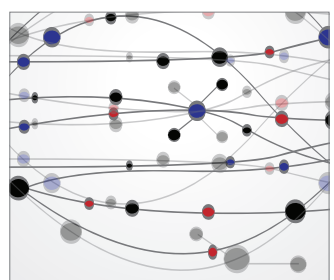

\section{The Scientific} World Journal
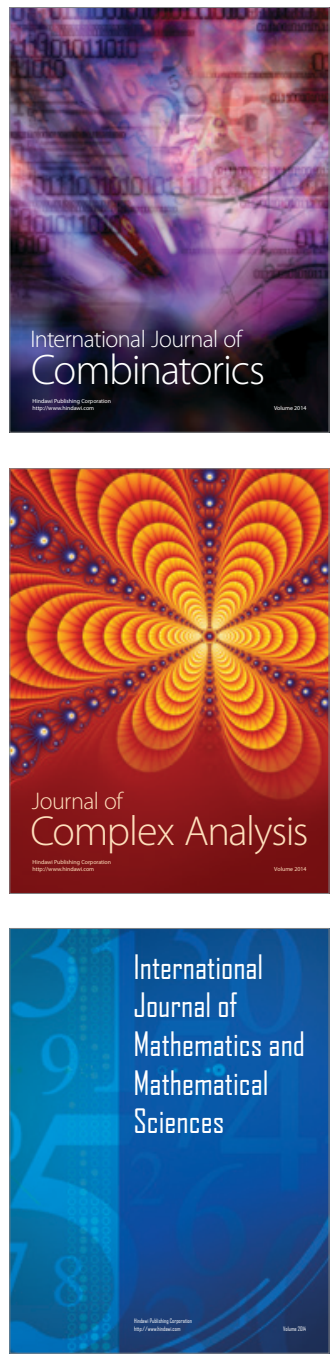
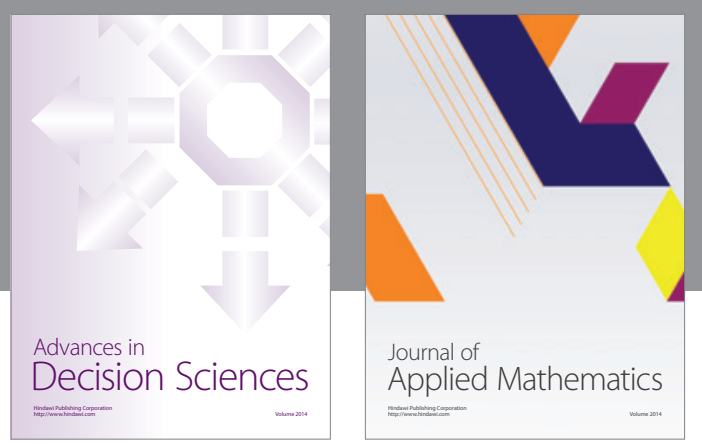

Algebra

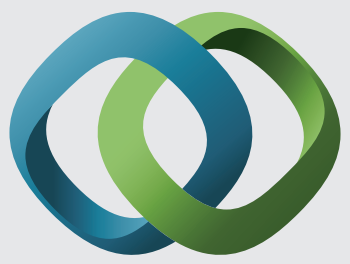

\section{Hindawi}

Submit your manuscripts at

http://www.hindawi.com
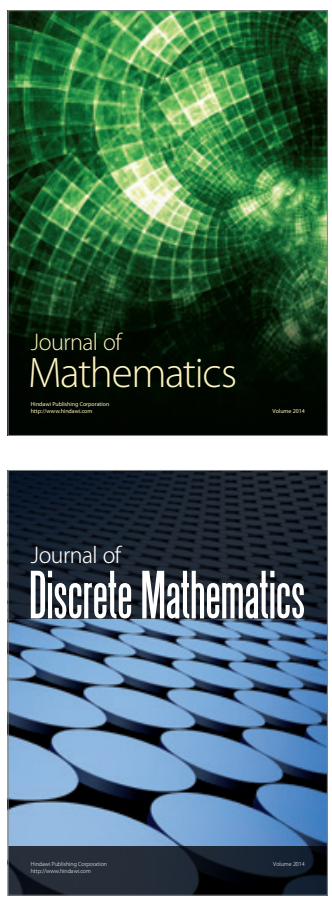

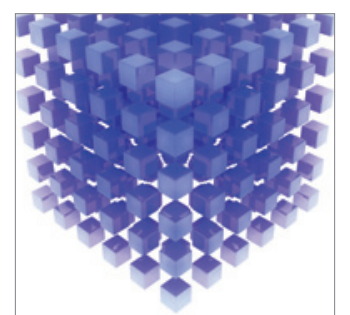

Mathematical Problems in Engineering
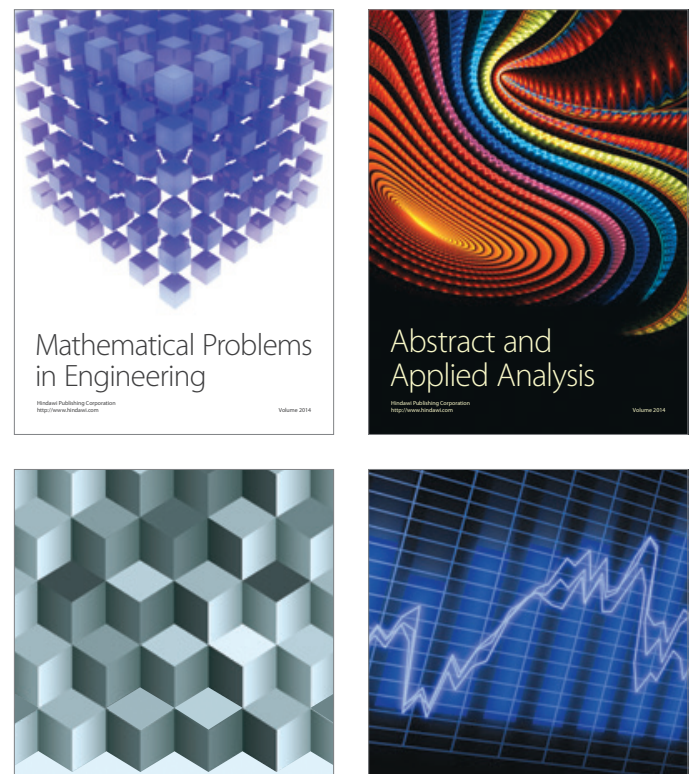

Journal of

Function Spaces

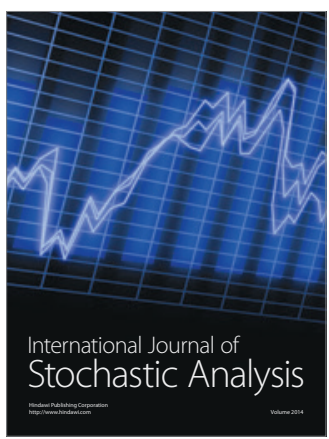

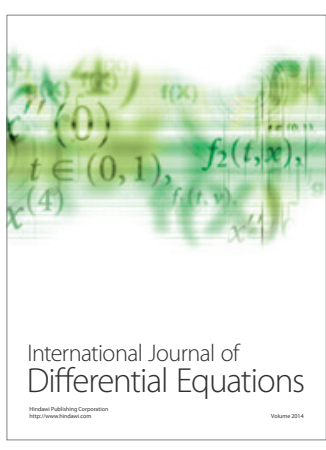
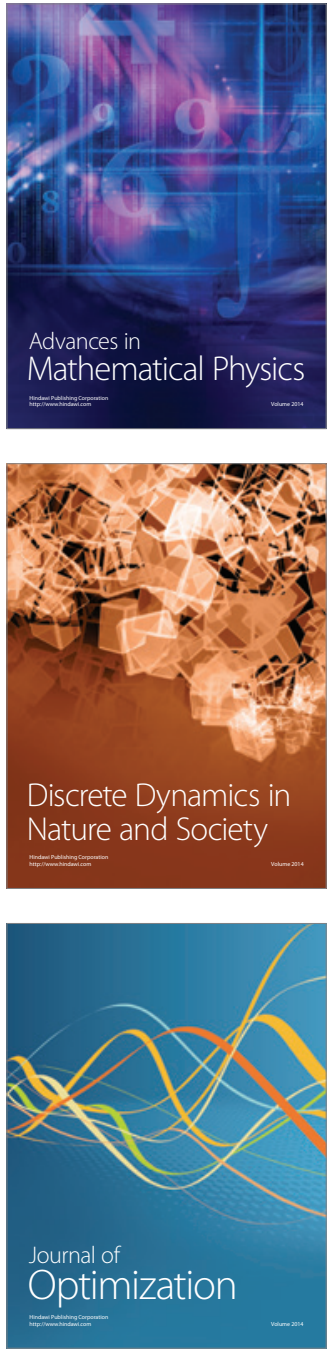